\title{
ANÁLISIS DE LOS PERSONAJES DE UN TEJIDO PARACAS: UNA INTERPRETACIÓN ICONOGRÁFICA DEL MANTO BLANCO'
}

\author{
LouRdes Chocano MENA ${ }^{\mathrm{ii}}$ \\ Arqueóloga, Colegio de Aroueólogos No. 040482 \\ rlchocano@gmail.com
}

\section{RESUMEN}

En este artículo se hace una descripción detallada de los motivos del Manto Blanco perteneciente a la colección textil del Museo de Arqueología y Antropología de la Universidad Mayor de San Marcos. Planteamos que el análisis de la indumentaria permite distinguir con claridad la identidad de género de los personajes antropomorfos representados y, por tanto, se presenta algunas pistas sobre el papel de la figura femenina en la cosmovisión Paracas. Se examinan también las técnicas de bordado y la combinación cromática. Por último proponemos una interpretación de las figuras del manto en términos de una escena ritual.

Palabras clave: Manto Blanco, bordados, indumentaria, túnica, anaco, personajes femeninos, plumas, huso, cabezas cercenadas, chamanismo, ritual, serpientes.

\section{ABSTRACT}

A thorough description of the iconography found in the "White Mantle", a piece belonging to the textile collection from Museum of archeology and anthropology at the National University of San Marcos, allows us to use clothing attire for distinguishing clearly the gender identity of the anthropomorphic personages represented. On that basis some clues about the role of feminine images in the worldview of Paracas culture can be suggested. Also embroidering techniques and chromatic combinations are examined. Finally, an interpretation of the figures of the mantle as representing a ritual scene is suggested.

KeYwords: White Mantle, clothing attire, embroiders, tunics, anacos, feminine personages, cut heads, feathers, spindle, shamanismo, serpents, ritual.

i Un primer análisis de este manto se presentó en la Primera jornada sobre el estudio y conservación de textiles. Publicado con el título "El manto blanco de Paracas Necrópolis". En: Recuperando nuestros textiles ... ayer y hoy. Olga Sulca, comp., San Miguel de Tucumán, Argentina. 2006. ISBN 10 (950-554-512-6). formato digital, texto 08 "Textiles arqueológicos".

ii Arqueóloga por la Universidad Nacional Mayor de San Marcos. Consultora en conservación de textiles formada por la UNESCO. Ha realizado estudios de postgrado en universidades extranjeras. Actualmente trabaja en la catalogación de piezas del Patrimonio Cultural de la Nación. 
La cultura Paracas se caracteriza por los bellos mantos y tejidos encontrados principalmente en contextos funerarios. Uno los aspectos más interesantes en dicha tradición textil es la iconografía a través de la cual es posible descubrir muchos aspectos de su cosmovisión. En este artículo nos ocupamos del llamado Manto Blanco, espécimen de la colección del Museo de Arqueología y Antropología de la Universidad Nacional Mayor de San Marcos, donado en los años treinta cuando el Dr. Julio C. Tello era su director.

En el análisis del conjunto de figuras de dicho manto es importante detectar los roles de género, una cuestión generalmente soslayada en los estudios realizados sobre la iconografía Paracas. El rol femenino ha sido asociado casi siempre a la maternidad y fue descrito por primera vez para esta cultura por Rebeca Carrión Cachot (1923: 329-331). Los trabajos de Sophie Desrossiers del Horizonte Tardío e Intermedio Tardío establecen la diferencia en la vestimenta según el sexo a partir del sentido de las aberturas de las túnicas así como del sentido de las urdimbres y tramas en el momento de elaborar y usar una prenda; las aberturas verticales se asocian al género masculino y las aberturas horizontales, al femenino. Del mismo modo, las decoraciones de listados que son verticales: son masculinas, y las horizontales, femeninas. (Desrossiers: 1992: 25, 26). Los estudios sobre las vestimentas procedentes de Ica confirman el uso de puntadas, aberturas y listas horizontales para las túnicas femeninas (Rowe 2001: 101-106). Posteriormente los hallazgos de Cahuachi (Nasca) muestran un vestido femenino con costuras, aberturas y listados horizontales (Frame 2008: 148). Esto sugiere que la vestimenta femenina andina no sufrió grandes alteraciones a través del tiempo y es probable que sus orígenes formales se sitúen mucho más atrás, sea en la época Arcaica o en el Precerámico Tardío.

A partir de la idea de que las representaciones en los tejidos se pueden referir a eventos del ciclo vital (Arnold 2000: 1-11), consideramos que podemos analizar al Manto Blanco como el retrato de un conjunto de personajes de distinto sexo que participan en algún tipo de ritual. La indumentaria, los accesorios y otros elementos permiten deducir el papel que desempeñó cada personaje en este evento.

\section{LA ESTRUCTURA Y LA MANUFACTURA DEL MANTO}

Como la mayoría de los mantos Paracas, el Manto Blanco tiene forma rectangular, 278 x $138 \mathrm{~cm}$, medidas que incluyen los flecos colocados en los cuatro bordes (Figs. 1 y 2). La longitud de los flecos es $3,5 \mathrm{~cm}$. La parte central es crema, de allí el nombre de "manto blanco". Se usaron para su confección el algodón y el pelo de camélido.

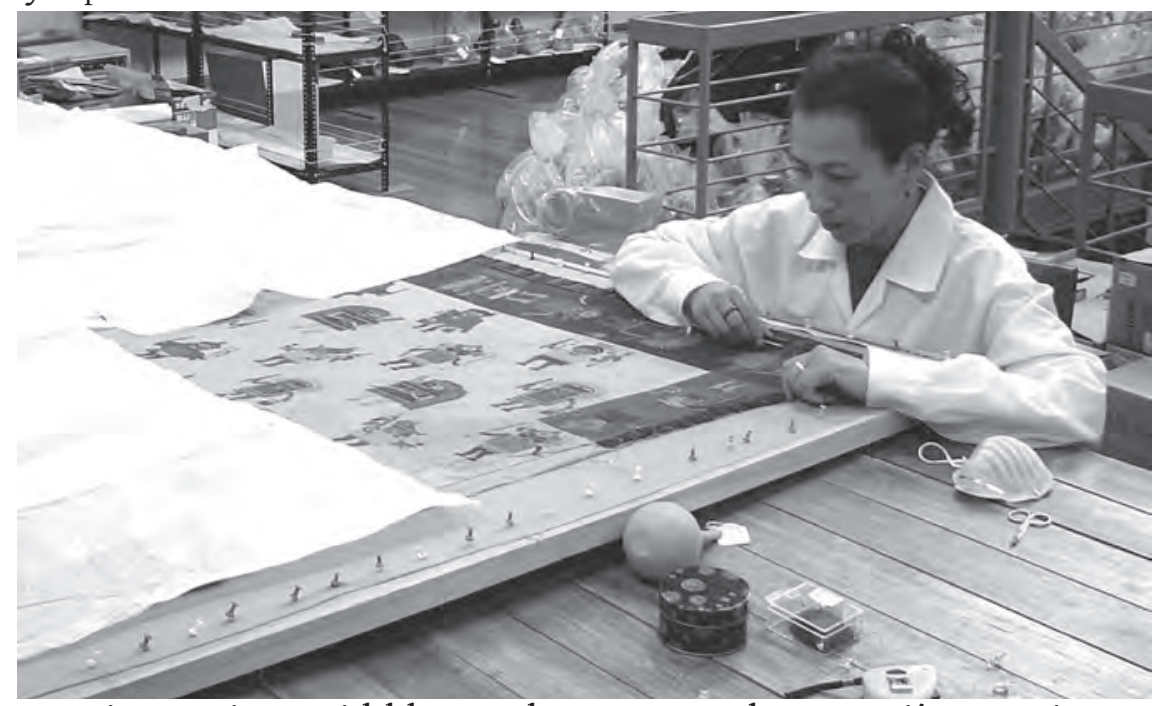

Figura 1. Vista parcial del Manto Blanco en proceso de conservación y montaje. 


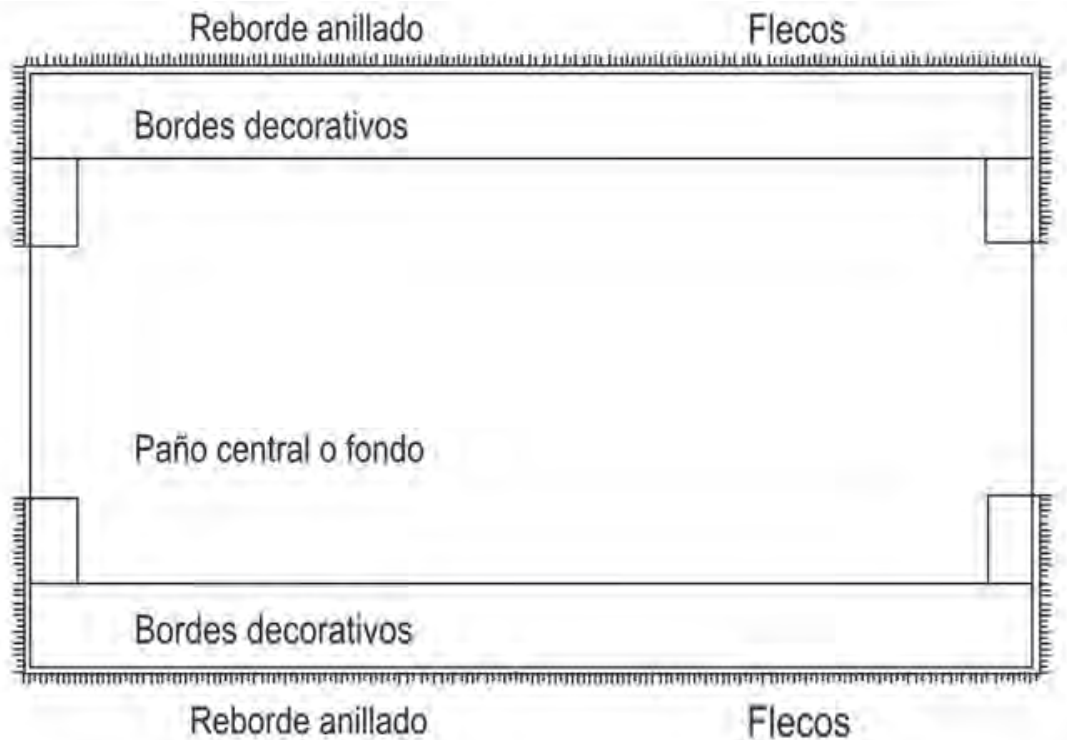

Figura 2. Estructura del manto. Dibujo de Lourdes Chocano.

\section{Estructura}

El manto se ha confeccionado a partir de tres paños: un paño central de fibra de camélido con tonos que van del crema original al beige (producto de la oxidación gradual de las fibras); este paño tiene 92 personajes bordados. A dicho paño se le han añadido dos paños angostos de algodón de color natural beige oscuro, uno a cada lado (Fig. 3), estos miden entre 14 y $13 \mathrm{~cm}$ de ancho por $268 \mathrm{~cm}$ de largo y han sido bordados con hilo morado para conformar un fondo sobre el cual, a su vez, se han bordado catorce personajes en cada uno de ellos.

El paño central mide $102 \mathrm{~cm}$ de ancho y $267 \mathrm{~cm}$ de largo. Es probable que este se hiciera con telar de piso o diagonal, y no con telar de cintura, pues los paños de telar de

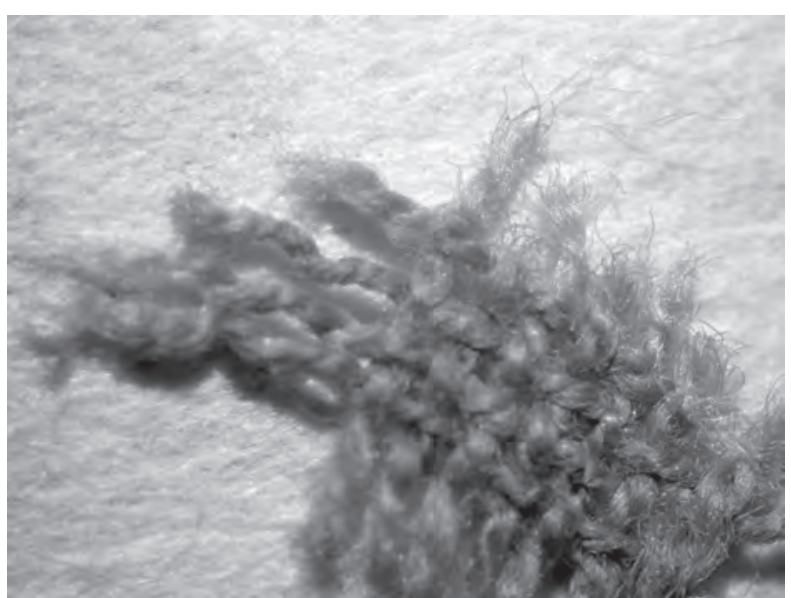

Figura 3. Vista macroscópica del tejido del paño central del manto. Fibra de camélido de color natural. cintura no pasan de $75 \mathrm{~cm} \mathrm{u} 80 \mathrm{~cm}$ "porque la anchura del paño sobrepasaría la envergadura de los brazos del tejedor". Sobre este paño están bordadas las bandas decorativas o bordes verticales entre las cuales queda un espacio de $46 \mathrm{~cm}$ a ambos lados del manto. Las bandas miden $12 \mathrm{~cm}$ de ancho por $27 \mathrm{~cm}$ de largo.

Los tres paños fueron unidos por uno de sus orillos longitudinales con punto surjete (puntada por encima) realizado con un hilo fino de pelo de camélido similar al del paño central; las puntadas de la costura son pequeñas (4 mm aproximadamente) y ligeramente diagonales. Las diminutas puntadas indican que se procuraba disimular la unión entre estos. Este tipo de puntada se halla muy difundida en los tejidos Paracas, aunque también se encuentra en otros estilos de tejidos de otras culturas tempranas y tardías. 
La cantidad de urdimbres por trama (1 x 1) le da una apariencia de tejido equilibrado: la trama (elemento activo) cruza por encima una urdimbre (elemento pasivo) y por debajo a la siguiente. Esta secuencia se mantiene hasta llegar al extremo del telar, a partir de allí la trama da la vuelta y entonces cruza las urdimbres invirtiendo el orden: las que están por encima ahora se cruzan por debajo, y las que se cruzaron por debajo ahora lo hacen por encima. De esta manera, los dos elementos son visibles por ambas caras del tejido, siendo el derecho y el revés idénticos; esto es lo que le da la apariencia de pequeños cuadrados en ambas caras (Fig. 4).

El campo central del Manto Blanco muestra un tipo de tejido preponderantemente regular y proporcionado: por centímetro cuadrado se han contado desde 20 urdimbres por 19 tramas a 17 urdimbres por 16 tramas. En los paños laterales de las bandas longitudinales bordadas, la

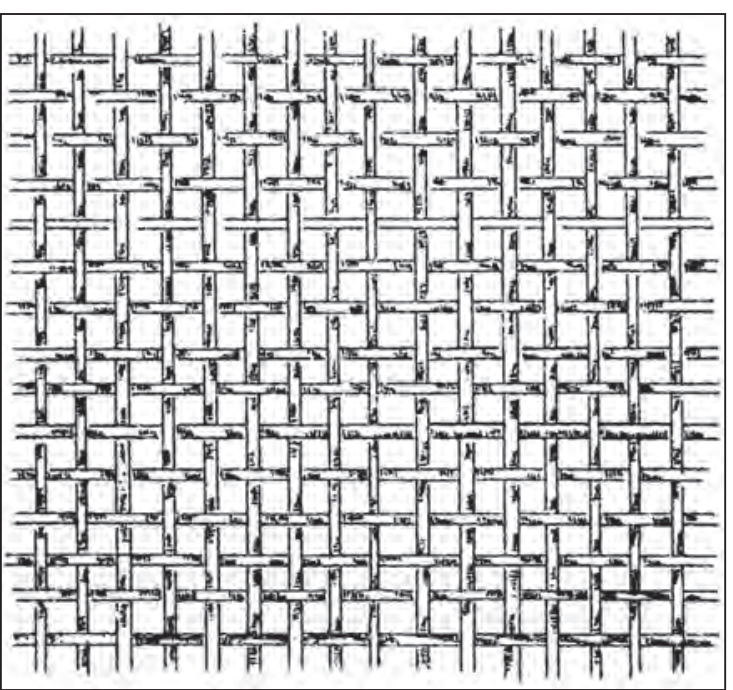

Figura 4. Técnica básica del manto. Tejido llano balanceado.

tela llana ha sufrido ciertos desplazamientos debido a que se ha juntado tramas y urdimbres, creando a primera impresión un tejido irregular.

Otra característica del paño central es que presenta estrellas o asteriscos bordados en gran cantidad alrededor de los personajes.

Los hilos presentan uniformidad de las urdimbres y las tramas, e igual retorsión y torsión. El grado de retorsión es variable por el tipo de material, es decir, se trate de algodón o fibra de camélido. Sus características para cada área del manto se pueden apreciar en la tabla de abajo.

El color original del fondo debió ser blanco que al paso del tiempo y producto del ambiente se ha oscurecido, tornándose beige claro o cremoso; este color de fondo es poco común entre los mantos hallados y estudiados, tal vez porque un manto con esta característica era destinado a algún personaje no sólo de alto estatus social sino que posiblemente a un chamán, cabe preguntarnos si este era hombre o mujer. La elaboración de este manto debió de ser una actividad colectiva y organizada. Los bordadores posiblemente se distribuyeron para tener facilidad de manipular la tela para que el resultado de la obra lograra una alta calidad. Las bandas laterales de $266 \mathrm{~cm}$ de largo por $14 \mathrm{~cm}$ de ancho permiten que el espacio sea compartido cómodamente por más de tres personas. Los paños debieron de estar extendidos en bastidores con dos finalidades: primero, para que al bordar no se frunciera la tela de soporte, y, segundo, para que los bordadores se pudieran colocar para trabajar a lo largo y ancho de la tela. El proceso de la reconstrucción de elaboración de un manto Paracas ha sido examinado anteriormente por Anne Paul (Paul 1986: 19-30). Basándose en la diferencia de tamaño de las caras de los personajes que del manto del fardo 89, esta investigadora dedujo que fueron ocho personas las que hicieron el trabajo. En el caso del Manto Blanco existen diferencias de tamaños de los personajes que

\begin{tabular}{|c|c|c|c|c|}
\hline Partes & \multicolumn{2}{|c|}{ Paños laterales } & \multicolumn{2}{c|}{ Paño central } \\
\hline Elementos & Urdimbres & Tramas & Urdimbres & Tramas \\
\hline Material & Algodón & Algodón & Fibra de camélido & Fibra de camélido \\
\hline Retorsión & $\mathrm{S}(2 /)$ & $\mathrm{S}(2 /)$ & $\mathrm{S}(2 /)$ & $\mathrm{S}(2 /)$ \\
\hline Torsión & $\mathrm{Z}$ & $\mathrm{Z}$ & $\mathrm{Z}$ & $\mathrm{Z}$ \\
\hline Grado de retorsión & $35^{\mathrm{a}} \pm 40^{\mathrm{a}}$ & $35^{\mathrm{a}} \pm 40^{\mathrm{a}}$ & $40^{\mathrm{a}} \pm 45^{\mathrm{a}}$ & $40^{\mathrm{a}} \pm 45^{\mathrm{a}}$ \\
\hline
\end{tabular}


se deben al espacio que ocupan en los paños. Como hemos indicado, los ejemplares de los ocho personajes diferenciados por su atuendo y sus atributos físicos no aparecen en la misma cantidad, aunque suman un total de 120 figuras, las que divididas entre ocho hipotéticos bordadores, significaría que cada uno bordó quince figuras. Este cálculo es solo provisional y para una afirmación más fundada se hace necesario un estudio en detalle de las puntadas y su distribución dentro de las figuras. Por su-

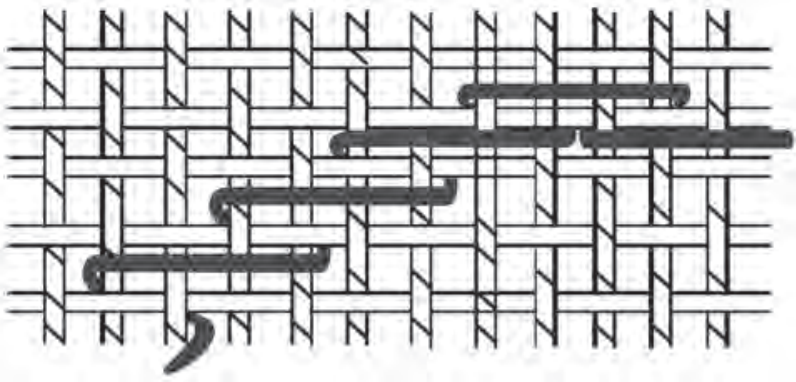

Figura 5. Bordado punto atrás. Dibujo de Lourdes Chocano. puesto, estas observaciones deben ser confrontadas con otros elementos y contextos arqueológicos, funerarios e iconográficos.

\section{Bordado}

El bordado es una técnica decorativa que se realiza utilizando hilos de pelo de camélido en dieciocho tonalidades de colores sólidos y matizados.

El punto de bordado más usado en el manto es el punto atrás, que sigue el patrón habitual de los tejidos Paracas: el hilo avanza en un solo sentido, tomando cuatro hilos de trama o urdimbre para luego retroceder dos (Fig. 5) ${ }^{1}$.

1. En los bordes decorativos longitudinales, el bordado de fondo de color morado se ha hecho siguiendo el hilo de la urdimbre, mientras que para los bordes verticales sigue el hilo de la trama. La puntada del bordado del fondo es uniforme. La dirección de la puntada es en Z (de izquierda a derecha), y se inclina de $70^{a}$ a $75^{a}$ aproximadamente. Hay entre quince y diecinueve hileras de puntadas aproximadamente por cada centímetro. Mientras que en los personajes, el bordado interior tiene diferentes inclinaciones: horizontales, verticales, diagonales (de izquierda a derecha o de derecha a izquierda), curvilíneas o concéntricas. Dependiendo de la sección bordada (partes del cuerpo, ropa o accesorios del personaje), la inclinación va desde $0^{\mathrm{a}}$ hasta los $90^{\mathrm{a}}$. Las diferencias y combinaciones de la inclinación de las puntadas dan movimiento y volumen a las figuras bordadas. (Fig. 8). La cantidad de hileras de puntadas en un centímetro longitudinal es de 21 a 22 hileras

2. Para el contorno de las siluetas de los personajes, así como para la delineación de los campos de color, se ha usado el punto atrás muy pequeño y apretado, que le da la apariencia de un cordoncillo, con lo que al usar un hilo de color diferente acentúa la sensación de relieve. En algunos contornos, el punto atrás es muy inclinado (más o menos 45ㅇ), por ejemplo en los tocados del personaje emplumado (Fig. 8).

3. Para detalles pequeños como dientes, ojos, etc. se usó el punto relleno, que consiste en puntadas verticales, pequeñas y muy compactas (Fig. 6). Algunos autores llaman satin stitch a este punto sin traducirlo adecuadamente, con lo que crean confusión e imponen una terminología innecesaria cuando existe la palabra en español ${ }^{2}$.

1 Algunos autores llaman a este punto "punto plano atrás", del inglés back plain stich. En este caso plain se refiere a la simplicidad de la puntada y no al relieve. Otras veces lo llaman punto cordoncillo o tallo. Algunas publicaciones en castellano ni siquiera lo traducen del inglés e insertan el nombre stem stitch. Este descuido genera confusión, pues lleva a creer que se trata de un punto de bordado distinto. Esto se debe en parte a que no se consulta la terminología ni la bibliografía en castellano existente. En especial, se dejan de lado los trabajos de Rebeca Carrión Cachot, quien fuera la primera en identificar los tipos de bordados en Paracas.

2 Es el caso de Jiménez (2009: 42). 


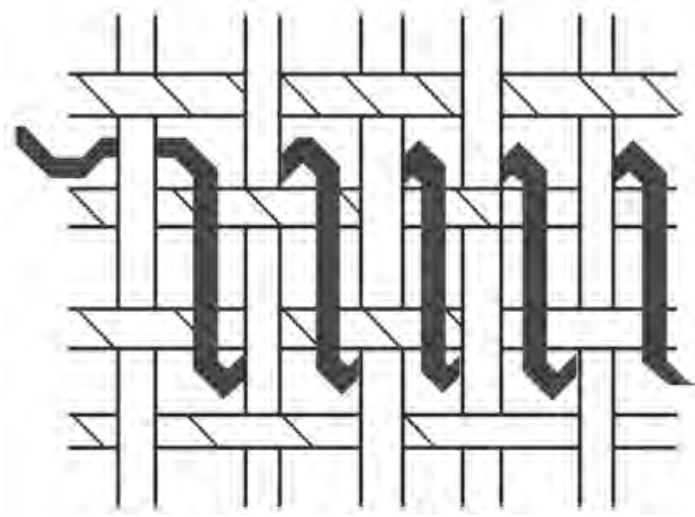

Figura 6. Bordado punto relleno. Dibujo de Lourdes Chocano.

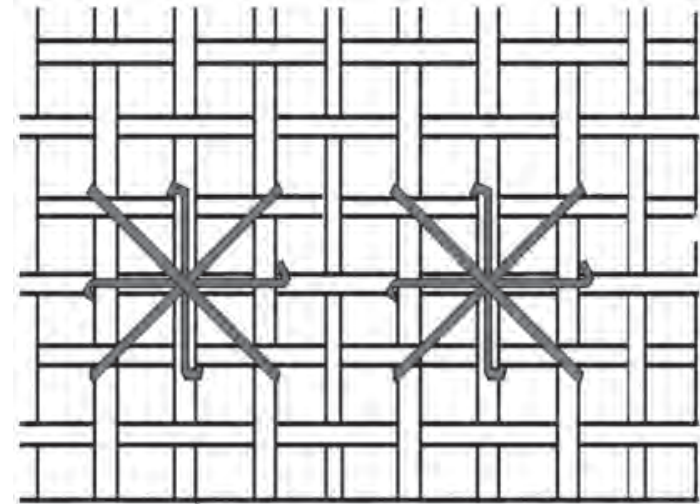

Figura 7. Punto doble cruz en el paño central del manto. Dibujo de Lourdes Chocano.

4. Finalmente, las estrellas o asteriscos se realizaron con el punto cruz doble, utilizando el mismo color y tipo de hilo del campo central del manto blanco (Fig. 7).

\section{Acabados.}

\section{El manto tiene:}

1. El reborde o ribete, elaborado con hilos morados, lleva un diseño de cruces de colores amarillo ocre, marrón, rojo, verde claro y oscuro. La técnica usada es anillado cruzado, típico de los acabados textiles de Paracas.

2. Los flecos estan retorcidos y colocados al orillo de los bordes morados del manto, intercalado con flecos de color amarillo ocre, marrón, rojo, verde claro y oscuro.

\section{Hebras, tonos y colores en el bordado}

En la cultura Paracas se suele combinar, en el hilado, dos hebras de diferente color para obtener un tercer color distinto; en este manto se puede observar que se torcieron una hebra de un color blanco y otra hebra de color rojo (retorsión S), y el resultado fue un hilo matizado de tonalidad rosada. En el cuadro de la siguiente página hemos sistematizado las combinaciones más notables.

En algunos colores (por ejemplo los verdes oscuros y claros) los tonos no provienen del mismo degradado y tal vez se deba al uso de los diferentes tintes o mordientes. La obtención de un color y su degradado es un tema de investigación que necesita experimentación adecuada, respaldada por un análisis químico, ya que el análisis visual por comparación no es suficiente. El color rojo en el manto blanco presenta dos tonalidades: una más oscura y otra más clara, pero tal vez esto se deba más al de-

Figura 8. Detalle de las puntadas del bordado, se aprecia diferente inclinación y dirección creando movimiento y textura. Detalle de fotografía de W. Salas. Cortesía del MAAUNMSM, 2004.

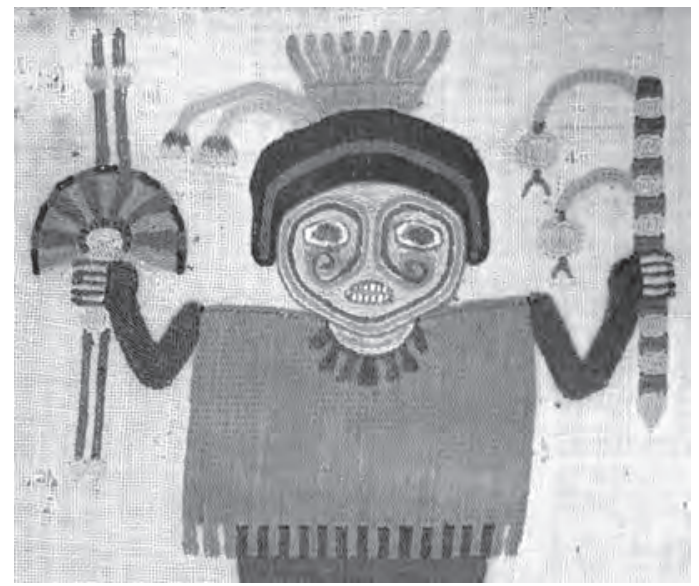


Lourdes Chocano / Análisis de los personajes del Manto Blanco: Una interpretación iconográfica

\begin{tabular}{|c|c|c|c|c|}
\hline COLORES & $\begin{array}{l}\text { Un solo } \\
\text { color }\end{array}$ & $\begin{array}{l}\text { Matizado (dos hebras de } \\
\text { diferente color) }\end{array}$ & $\begin{array}{l}\text { Torsión y } \\
\text { Retorsión de hilos } \\
\text { del bordado }\end{array}$ & $\begin{array}{l}\text { Grado de } \\
\text { Retorsión }\end{array}$ \\
\hline Amarillo & $\mathrm{X}$ & - & $2 \mathrm{Z}=\mathrm{S}$ & $40^{\mathrm{a}}$ a $50^{\underline{a}}$ \\
\hline Amarillo ocre & $\mathrm{X}$ & - & $2 \mathrm{Z}=\mathrm{S}$ & $40^{\mathrm{a}}$ a $50^{\mathrm{a}}$ \\
\hline Azul & $\mathrm{X}$ & - & $2 Z=S$ & $40^{\mathrm{a}}$ a $50^{\underline{a}}$ \\
\hline Azul claro & $\mathrm{X}$ & $\mathrm{X}$ (Blanco y turquesa) & $2 \mathrm{Z}=\mathrm{S}$ & $40^{\mathrm{a}}$ a $50^{\mathrm{a}}$ \\
\hline Beige & $\mathrm{X}$ & - & $2 Z=S$ & $40^{\mathrm{a}}$ a $50^{\mathrm{a}}$ \\
\hline Blanco & $\mathrm{X}$ & - & $2 \mathrm{Z}=\mathrm{S}$ & $40^{\mathrm{a}}$ a $50^{\underline{a}}$ \\
\hline Celeste & $\mathrm{X}$ & $\mathrm{X}$ (Azul y blanco) & $2 Z=S$ & $40^{\mathrm{a}}$ a $50^{\underline{a}}$ \\
\hline Gris & - & X (Blanco y negro) & $2 Z=S$ & $40^{\mathrm{a}}$ a $50^{\mathrm{a}}$ \\
\hline Marrón claro & $\mathrm{X}$ & - & $2 \mathrm{Z}=\mathrm{S}$ & $40^{\mathrm{a}}$ a $50^{\underline{a}}$ \\
\hline Marrón oscuro & $\mathrm{X}$ & - & $2 \mathrm{Z}=\mathrm{S}$ & $40^{\mathrm{a}}$ a $50^{\underline{a}}$ \\
\hline Morado & $\mathrm{X}$ & - & $2 Z=S$ & $40^{\mathrm{a}}$ a $50^{\mathrm{a}}$ \\
\hline Negro & $\mathrm{X}$ & - & $2 \mathrm{Z}=\mathrm{S}$ & $40^{\mathrm{a}}$ a $50^{\mathrm{a}}$ \\
\hline Rojo & $\mathrm{X}$ & - & $2 Z=S$ & $40^{\mathrm{a}}$ a $50^{\underline{a}}$ \\
\hline Rosado & $\mathrm{X}$ & $\mathrm{X}$ (b/rojo) X (b/beige) & $2 \mathrm{Z}=\mathrm{S}$ & $40^{\mathrm{a}}$ a $50^{\mathrm{a}}$ \\
\hline Turquesa claro & $\mathrm{X}$ & - & $2 Z=S$ & $40^{\mathrm{a}}$ a $50^{\mathrm{a}}$ \\
\hline Turquesa oscuro & $\mathrm{X}$ & $\mathrm{X}$ & $2 \mathrm{Z}=\mathrm{S}$ & $40^{\mathrm{a}}$ a $50^{\mathrm{a}}$ \\
\hline Verde claro & $\mathrm{X}$ & $\mathrm{X}$ (blanco y verde oscuro) & $2 \mathrm{Z}=\mathrm{S}$ & $40^{\mathrm{a}}$ a $50^{\underline{a}}$ \\
\hline Verde oliva & $\mathrm{X}$ & - & $2 \mathrm{Z}=\mathrm{S}$ & $40^{\mathrm{a}}$ a $50^{\underline{a}}$ \\
\hline Verde oscuro & $\mathrm{X}$ & - & $2 \mathrm{Z}=\mathrm{S}$ & $40^{\mathrm{a}}$ a $50^{\mathrm{a}}$ \\
\hline
\end{tabular}

terioro por exposición, sin protección, a los rayos ultravioletas (UV). También el proceso de oxidación de las fibras u otras aplicaciones que ha experimentado el tejido a lo largo del tiempo, han alterado el color teñido o natural de la fibra.

El tipo de retorsión nos indica que se trata de hilos bien retorcidos, fuertes y algo enroscados, aunque no llegan a ser del tipo crepé. Por ello, los bordados Paracas, incluso el del Manto, tienen textura y volumen.

Finalmente, una parte de las bandas decorativas, el bordado del fondo y algunos detalles de los personajes, esto indica el proceso y orden de elaboración del manto se notan inconclusos: primero se bordaron los porciones más grandes de los personajes, luego los detalles: ojos, vestidos, etc. y finalmente el fondo de morado que se haría por sectores donde ya se había concluido con el bordado de los personajes $^{3}$ (Fig. 9).

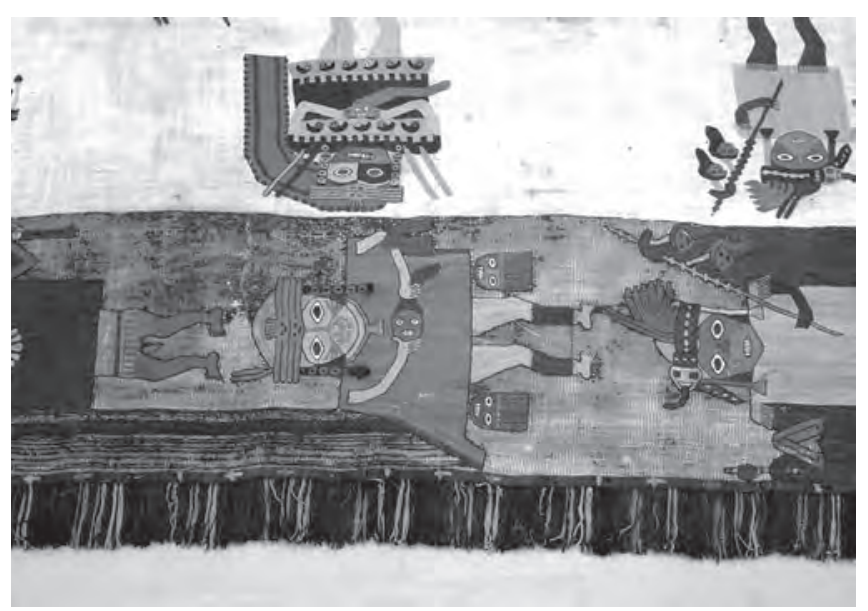

Figura 9. Porción del manto que inconcluso por los bordadores Paracas. Fotografía de W. Salas. Cortesía del MAA-UNMSM, 2004.

3 Tejidos inconclusos se han hallado en algunos ajuares de los fardos Paracas; una esclavina, especimen № 50 y un turbante, especimen № 48, del fardo 290 de la colección del MNAAHP. 


\section{ANÁLISIS Y DESCRIPCIÓN DE PERSONAJES E INDUMENTARIA EN EL MANTO}

En total se han identificado ocho personajes representados en 120 versiones, a los que he clasificado con letras de la A hasta la $\mathrm{H}$. Dichos personajes también están representados en otros mantos o prendas Paracas 4 . La descripción de los personajes comienza por el borde izquierdo (Fig. 18). Este orden es arbitrario y se hace para facilitar la comprensión de la secuencia cromática y rítmica de los personajes.

Personaje A: Figura femenina debido a que la túnica lleva aberturas horizontales. Esta prenda le cubre las rodillas, es de color amarillo ocre, no tiene decoración, y presenta flecos en las mangas y en el ruedo. En los bordes del manto la túnica de dos de los personajes A es de color verde. Presenta un tocado que consiste en una cinta roja ${ }^{5}$ (vincha o "llauto") decorada con detalles azules, amarrada alrededor de la cabeza y rematada en una serpiente con los ojos abiertos y con la boca abierta mostrando la lengua elevada hacia arriba. Las puntadas del bordado de la cinta son horizontales, mientras que los detalles de la decoración se van formando por puntadas de orientación semicircular. De esta cinta salen por encima de la cabeza seis serpientes pequeñas y ondulantes, contorneadas con hilo verde y rojo, que se inclinan hacia el lado izquierdo. El cabello no se es visible. La parte superior de la cabeza, la coronilla, sobresale por encima de la cinta o "llauto", por lo que pienso que se trata de la representación de un personaje con deformación craneana. Finalmente, de la cinta (llauto) caen dos colgantes a cada lado de la cara rematados en un triángulo.

Lleva el rostro pintado de rojo y verde oliva. Los campos de color están divididos por una línea escalonada, que va desde la parte inferior de una de las mejillas hasta la altura de la nariz y baja nuevamente hasta la mejilla opuesta. La nariz no está definida, se supone que está enmarcada por la línea divisoria de los colores del rostro. Los ojos y la boca son de forma rectangular, delineados en color morado. Muestra unos dientes rectangulares.

Las extremidades son de color verde oscuro, los brazos son tan largos como las piernas. Tiene extendido el brazo derecho y a la altura del codo lleva un objeto de color rojo, semejante a un pequeño paño. Se han encontrado pequeños paños rectangulares en los fardos Paracas, los cuales servían para guardar instrumentos y materiales textiles (Tello y Mejía 1979: 359,360). En las ilustraciones de Guaman Poma de fiestas como la del sol durante el Haucay kuski (descanso de la cosecha), de los Chichaysuyos y de los Collasuyos, mujeres y hombres llevan un paño en el antebrazo, tal vez como elemento ceremonial (Guaman Poma 1987: 239, 323, 327).

En la mano derecha sostiene un instrumento alargado listado dos colores: rojo y marrón, que termina en una borla de color verde claro. Se trata de un huso con un ovillo de hilo. En el brazo izquierdo lleva una vara o caña de la que cuelgan dos pequeñas cabezas. Estas cabezas tienen ojos, boca y cabellos, y son tal vez la personificación de copos de algodón. Tiene los pies descalzos y lleva ajorcas anchas de color verde, decoradas con pequeños cuadrados rojos que hacen juego con su vincha o "llauto" (Fig. 10).

Personaje B: Se le identifica como personaje masculino por su indumentaria consistente en un uncu verde oscuro que le llega a la altura de la cadera y con flecos en el borde (otros ejemplares de este personaje llevan un uncu rojo). Sobre el uncu tiene una especie de pectoral triangular de color amarillo ocre que llega hasta el centro del pecho y termina en flecos a manera de adorno. Lleva un taparrabo

4 Rebeca Carrión Cachot (1931) en su estudio sobre la indumentaria Paracas realizó una clasificación iconográfica, donde muchos de los personajes de este manto aparecen como ejemplos, pero no definió el género de estos personajes.

5 Los colores aquí descritos no siempre son recurrentes en los detalles de los accesorios. 
o wara amarillo ocre con flecos pequeños y ligeramente triangulares, y con una lista delgada en el borde de color marrón. La forma de este taparrabo es semicircular.

Lleva un tocado compuesto por un turbante, una diadema y una punta de lanza. El turbante es de color amarillo ocre con dos listas verdes, y se prolonga hacia un lado llegando hasta la cintura del personaje. En otras variantes el turbante es verde con listas amarillas. La punta de lanza aparece sobre el tocado, directamente sobre el centro de la cabeza, al parecer servía para sostenerlo. En la parte frontal lleva una doble diadema de color marrón, en cuyo centro hay dos caras con ojos y boca, tal vez de felino. El personaje tiene a cada lado de la cara dos trenzas, adornadas con discos de oro. La cara está pintada con líneas diagonales roja y turquesa. Otros ejemplares de este personaje aparecen con la cara pintada de verde y amarillo ocre. Tiene cejas negras ligeramente arqueadas, los ojos están delineados de color oscuro, la boca ovalada está abierta mostrando una dentadura rectangular y no tiene nariz.

Las extremidades son de color rojo. La figura extiende los brazos hacia la izquierda, en una mano sostiene un abanico, y en la otra una borla de color marrón con mango verde. En otros casos, la figura lleva un báculo de dos colores verde oscuro y amarillo ocre. Tiene los pies descalzos y unas ajorcas verdes le rodean los tobillos.

El personaje B en la versión de la parte central del manto incorpora más atributos: en el rostro muestra una serpiente bordada en color rosado. La serpiente le rodea la boca y los ojos haciendo una $\mathrm{S}$ en algunos casos y en otras haciendo una Z. La cola de la serpiente bordea la boca, el cuerpo rodea los ojos y la cabeza descansa en la mejilla. El color de esta serpiente es siempre oscuro (marrón o morado) y está delineada. El resto de los atributos del personaje son los mismos que aparecen en los ejemplares B del borde, a excepción de uno ubicado cerca del borde izquierdo, al que llamaremos personaje B1, el cual además de la serpiente, lleva una antara o zampoña, que sostiene con la mano izquierda, mientras que en la mano derecha lleva un abanico. La antara es de cinco tubos o cañas de color marrón (Fig. 11).

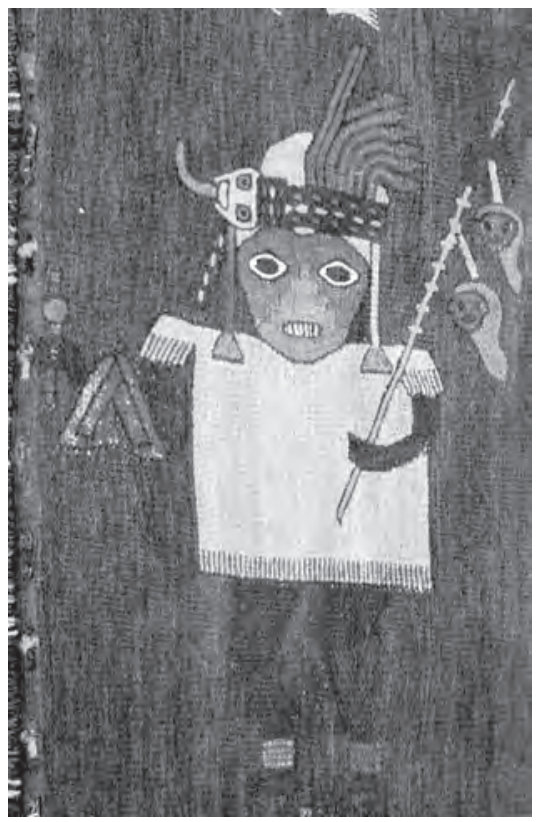

Figura 10. Personaje A propuesto como femenino, lleva un huso y ovillo. Fotografía de W. Salas, cortesía del MAA-UNMSM, 2004

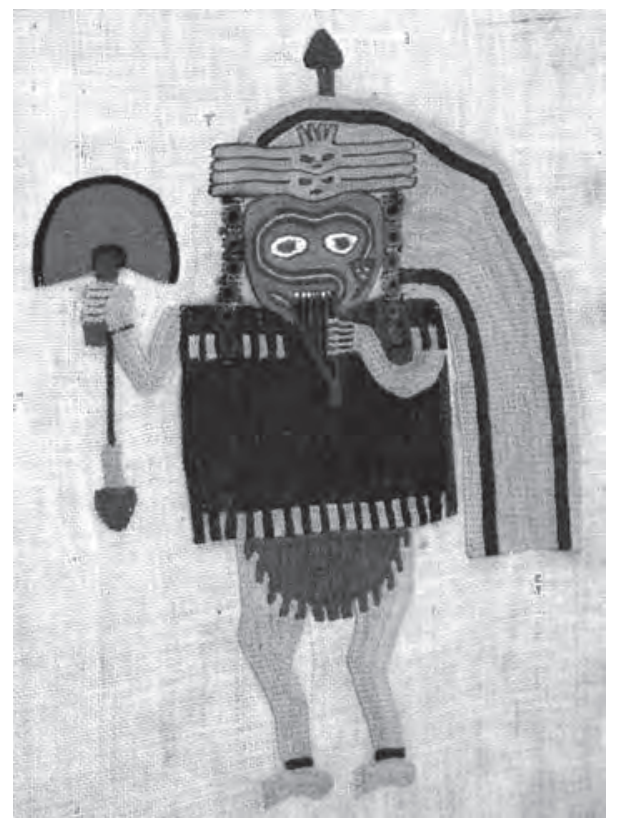

Figura 11. Personaje B1, masculino, lleva una antara y abanico. Fotografía de W. Salas, cortesía del MAAUNMSM, 2004 
Personaje C: Se trata de un personaje masculino muy peculiar pues representa un ave, tal vez un cóndor. La cabeza está cubierta por un turbante de color verde y amarillo ocre, una banda del cual cae hacia un costado. Una punta de lanza aparece encima de la parte central de la cabeza. No se ve el cabello. El rostro está pintado desde las mejillas con bandas horizontales en las que hay pequeños rectángulos. La nariz de este personaje está representada por una delgada línea vertical que comienza en la frente y pasa entre los ojos; por lo que más podría tratarse de la representación de un pico de ave. Los ojos y la boca están delineados. La boca está abierta y tiene la forma de una V muy abierta exhibiendo una dentadura rectangular.

Debajo de la cara presenta un collarín redondo como el de los cóndores, de color marrón claro, tiene dos alas de color verde oscuro abiertas una a cada lado, colocadas detrás de los brazos. También tiene una cola de ave que le llega hasta los muslos, asomando por el costado derecho de su faldellín. Lleva un uncu de color rojo (amarillo en algunos ejemplares), sin decoración y sin flecos en el ruedo que le llega hasta la cintura. El faldellín es de color azul, a veces amarillo muy corto, con una lista horizontal roja cerca del ruedo que termina en flecos.

Las extremidades son de color amarillo ocre y en algunas variantes verde. La figura tiene los brazos abiertos; en la mano izquierda lleva un báculo de dos colores con la punta hacia abajo, en la mano derecha lleva una vara con colgantes que pueden ser sonajas. Tiene los pies descalzos con ajorcas verde oscuro en los tobillos ${ }^{6}$ (Fig. 12).

Personaje D: Este es el personaje conocido como el dios volador se caracteriza por un penacho radial a manera de aureola. El penacho radial es de color marrón. Lleva una doble diadema con rostros en el centro, similar a la que porta el personaje B. A semejanza de este, el personaje D también tiene el cabello separado en trenzas colocadas a cada lado de la cara, y adornadas con discos.

La cara es casi ovalada, y lleva una pintura facial de un color rojo exclusivamente y una inmensa nariguera de color amarillo ocre le cubre las mejillas y la boca. La nariz está definida por una línea que nace de la frente hasta la altura de la nariguera que parece representar el pico de un ave. Los ojos están delineados con hilo morado. Lleva un collar corto con un colgante de forma triangular de color turquesa.

Viste un uncu amarillo ocre (en otros ejemplares es verde o morado), que llega hasta la cintura, con una lista verde oscuro que marca todo el contorno. Lleva un taparrabo o wara rojo de forma semicircular, con una lista horizontal en el borde de color azul que termina en flecos. Por el costado derecho debajo del uncu le cuelga una faja listada de dos verde y amarillo que le llega hasta los muslos. Algunos de los ejemplares en la parte central llevan un faldellín de color verde. Las extremidades son verde oscuro. Con una mano sujeta un báculo listado de dos colores, que termina en una punta orientada hacia abajo. En la otra mano sujeta por los cabellos una cabeza ${ }^{7}$. Unas ajorcas de color amarillo ocre adornan sus pies descalzos (Fig. 13).

Personaje E: Este personaje masculino tiene un turbante de color verde oliva con decoración de lunares rojos, el turbante le cubre toda la cabeza y no deja ver ningún cabello suelto. Lleva una diadema grande amarilla con un disco al centro que tiene seis lóbulos dispuestos de dos en dos: dos hacia arriba, dos al lado izquierdo y los otros dos al lado derecho. Al lado izquierdo a la altura de la cabeza tiene unas cintas o sogas enrolladas, tal vez son parte del turbante o malla de este tocado que algunos personajes Paracas

6 Este personaje C aparece como principal en el manto número 14 del fardo 290, y en el especimen 44 del fardo 382.

7 Peters, Ann (2003 - 4 ) señala que el uso de cabezas trofeo no se puede atribuir a Paracas, donde más bien se trata de cabezas cercenadas. En Nasca las cabezas cercenadas si fueron tratadas como cabezas trofeo. 


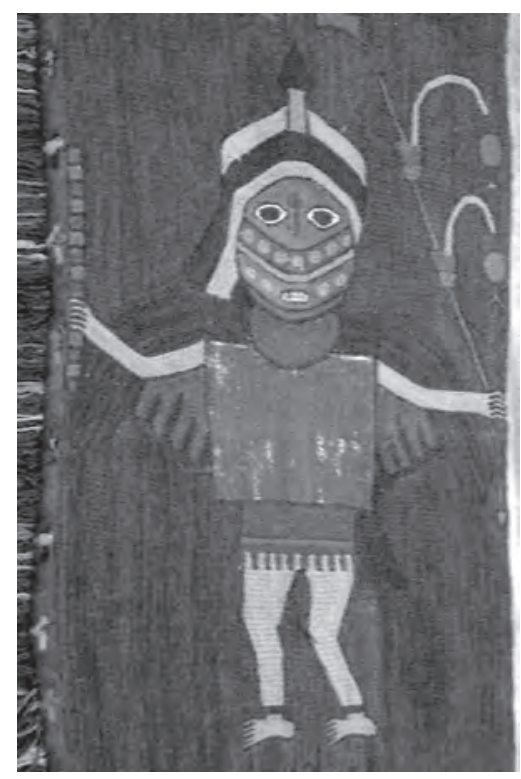

Figura 12. Personaje C, personificando un cóndor. Fotografía de W. Salas, cortesía del MAA-UNMSM, 2004.

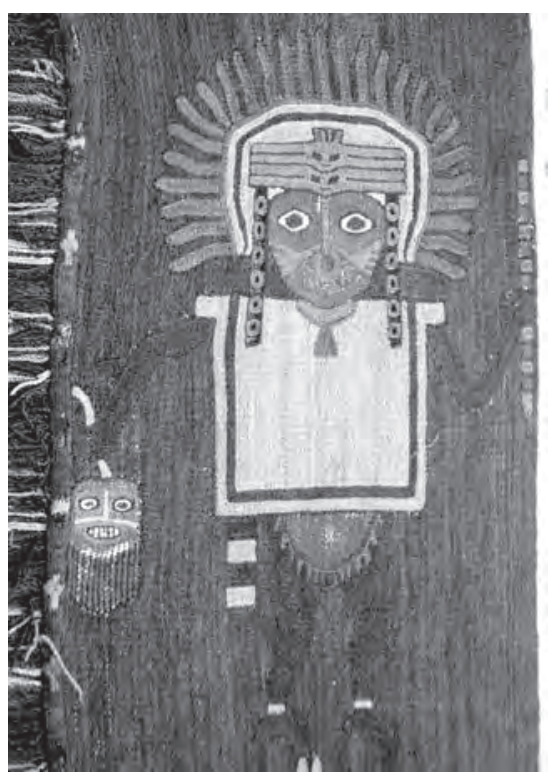

Figura 13. Personaje D, masculino, de mayor rango. Fotografía de W. Salas, cortesía del MAA-UNMSM, 2004

tenían ${ }^{8}$. La cabeza es grande al igual que el rostro, con una pintura facial que lo cubre casi todo a manera de máscara. La nariz no está delineada, la boca es rectangular y enseña los dientes rectangulares así como la lengua, representada con un fino hilo rojo. Lleva un uncu corto de color verde oscuro que le llega hasta la cintura, con listas verticales amarillas a los lados y en la parte interior, listas en paralelo. Un faldellín corto de color amarillo ocre le cubre hasta la mitad de los muslos, decorado con una lista azul marino horizontal en el ruedo, que termina en flecos. Otra versión de este personaje que aparece en los bordes morados lleva un taparrabo en vez de un faldellín.

Las extremidades son rojas. En la mano izquierda, el personaje sostiene un báculo de dos colores: amarillo ocre y verde oscuro con una punta hacia arriba. En la mano derecha sostiene un arma, que parece una lanza con la punta hacia abajo. El arma tiene el lado derecho aserrado y, como remate, un objeto que parece una mano mutilada, que tal vez podría haber tenido la función de amuleto o reliquia. Como los anteriores, tiene los pies descalzos y ajorcas verdes que le rodean los tobillos (Fig. 14).

Personaje F: Este personaje aparece en otros mantos Paracas y se le atribuye el sexo femenino por la vestimenta. Su cuerpo presenta una mayor anchura con respecto al resto de personajes. Lleva un tocado compuesto por un turbante verde oscuro con dos listas amarillo ocre y una doble diadema. El turbante es muy largo y le llega hasta las rodillas por detrás de la cabeza. La doble diadema es similar a las que adornan a los personajes B y D. Los cabellos también han sido dispuestos a cada lado de la cara en trenzas adornadas con discos.

La cara de este personaje tiene forma cuadrangular, pintada en forma de damero con cuatro cuadrantes. Tiene los ojos delineados, la boca en forma rectangular mostrando la dentadura. No tiene nariz.

8 E. Yacovleff, y J. C. Muelle: “Un fardo funerario de Paracas”. En: Revista del Museo Nacional, Tomo III, 1934, nº 1 y 2.63-138, ilustran un posible uso de un turbante de mallas (en figura 17, p. 123). 


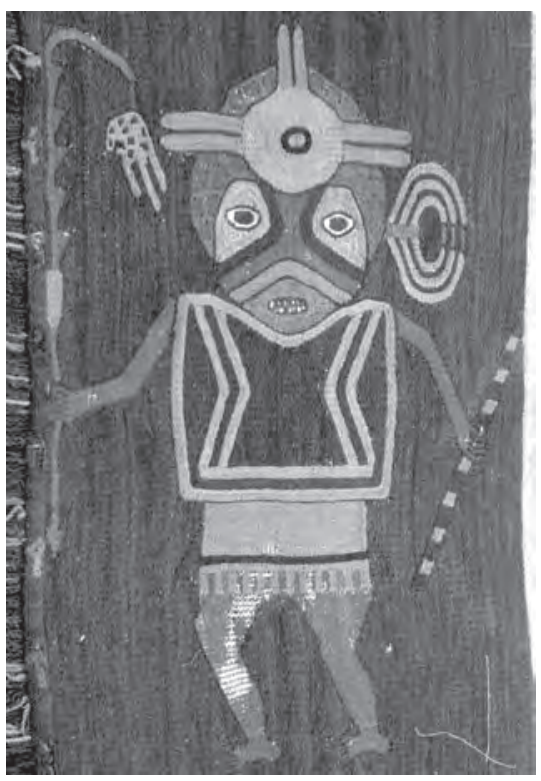

Figura 14. Personaje E, masculino. Fotografía de W. Salas, cortesía del MAA-UNMSM, 2004

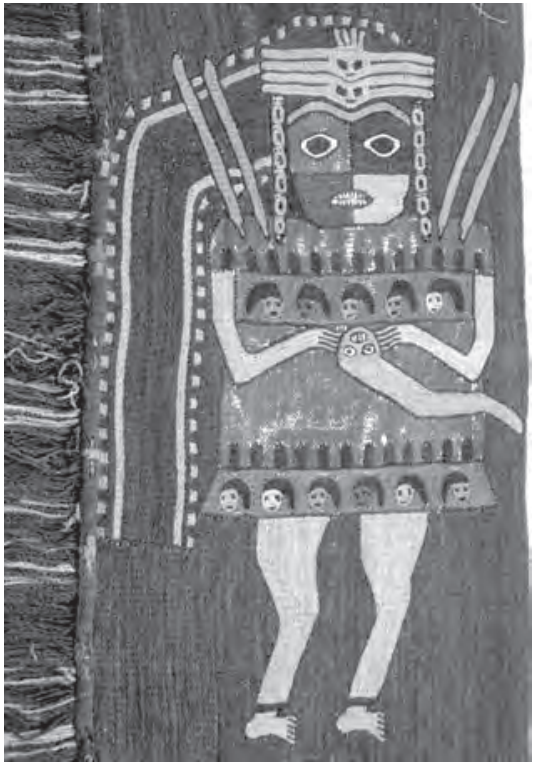

Figura 15. Personaje F, femenino, lleva tupus y cabezas en el vestido. Fotografía de W. Salas, cortesía del MAA-UNMSM, 2004

Lleva una túnica larga que le llega a medio muslo con flecos superiores e inferiores de colores rojo y verde (en otras versiones, la túnica es amarillo ocre y beige). A la altura del pecho, la túnica tiene una banda horizontal de flecos cortos, bajo los cuales aparecen cinco pequeñas cabezas dispuestas en sentido horizontal. Este motivo se repite en el ruedo inferior, aunque las cabezas son seis. Otro atributo en este personaje es que tiene cuatro varillas colocadas de dos en dos en cada hombro, que serían los tupus o alfileres con los que se sujeta una lliclla. Las extremidades son amarillo ocre y tiene los pies descalzos adornados con ajorcas verde oscuro. A la altura del pecho, el personaje sostiene entre las manos una cabeza, cuyos cabellos caen en forma ondulante pero recta hacia el lado izquierdo9 (Fig. 15).

Frame (2008: 248) describe un vestido femenino encontrado en Nasca, correspondiente al Intermedio Temprano, que se parece al que hemos descrito para este personaje. El anaco que se sigue utilizando en ocasiones festivas: Sondorillo (Piura) y Camillaca (Tacna), también véase las fotografías publicadas por Roel y Borja (2011).

Personaje G: El último personaje identificado como masculino, lleva un uncu amarillo ocre sin decoración, con flecos en la vasta, que llegan hasta la cadera. Tiene un taparrabo semicircular con flecos de color amarillo. En otros cuadros del manto este personaje lleva un faldellín corto de color amarillo ocre con una lista azul en el borde que termina en flecos que llegan a la mitad de los muslos.

Lleva un tocado formado por un penacho pequeño sobre un turbante listado que cubre toda la cabeza sin dejar ver el pelo. La cara está pintada con dos líneas de colores que dibujan el contorno del rostro y terminan en el centro formando una espiral en las mejillas. El contorno del rostro ha sido elaborado con puntadas curvas. El rostro de este personaje es ovalado y alargado. Los ojos también

9 Yacovleff y Muelle (1934: 85, fig. 4) estudiaron la momia 217, procedente de Cabeza Larga, aparece el personaje $\mathrm{F}$ en el manto número 10 (12-8802) de este fardo. (MNAAH). El mismo personaje aparece en el manto 7 del 382, en un manto del fardo 451 (Tello 1979). 
están delineados. No tiene nariz, la boca muestra unos dientes rectangulares. Se adorna con un collar corto de color turquesa y con pequeños pendientes rectangulares verde oscuro.

Las extremidades son de color verde oscuro. Tiene los brazos abiertos con los codos flexionados; en la mano derecha sostiene un báculo con la punta hacia abajo listado de dos colores: amarillo ocre y rojo, este báculo tiene en la parte superior unas sonajas, similares al que lleva el personaje C. En la mano izquierda lleva un abanico que tiene dos colgantes en el mango, el abanico tiene listas verticales de dos colores: amarillo y verde. Tras el abanico se proyectan dos varas delgadas con pequeños nódulos. Los pies descalzos se adornan con ajorcas de color amarillo ocre (Fig. 16).

Personaje H: Considero que es un personaje femenino porque aberturas de la manga de su túnica son horizontales (las prendas masculinas siempre tienen las aberturas verticales) y no lleva ninguna prenda masculina (taparrabo, faldellín o uncu). Para Frame (que le asigna la letra D) se trata de un personaje masculino de alta jerarquía por llevar una diadema de oro y porque lo asocia a un personaje que lleva una túnica similar en un tejido Paracas del Textile Museum (Frame 2008: 253- 255). La túnica del personaje $\mathrm{H}$ del manto blanco es de color verde y le llega hasta la mitad del muslo, con una especie de cola o apéndice.

En la cabeza lleva un tocado comparativamente simple formado por un paño de color rojo que le cubre totalmente la cabeza. En la parte frontal de la cabeza lleva una diadema doble similar a las descritas para los personajes B, D y F, pero de la parte izquierda de la diadema sale un instrumento textil en forma de horquilla: "kallapa" que sirve para jalar los hilos cuando se hila (Guaman Poma 1987: 297). Otros ejemplares de este personaje llevan este instrumento en la parte central del tocado. El hilado es una actividad que ejercen las mujeres exclusivamente, lo cual refuerza la identidad femenina del personaje. El cabello está arreglado en sendas trenzas adornadas con discos. La cara es grande, redonda y amarilla; lleva una gran nariguera que le cubre las mejillas y la boca. Los ojos están delineados. Tiene un collar corto grisáceo con un colgante de forma triangular de color amarillo.

El personaje tiene las extremidades rojas. A la altura del pecho sostiene una cabeza cercenada. Del brazo izquierdo le cuelga un instrumento en forma de $Y$, tal vez un instrumento textil. Del ruedo de la túnica cuelgan dos cabezas una a cada lado, volteadas de modo que los cabellos caen hacia abajo a manera de flecos. Tiene las pantorrillas verde oscuro con ajorcas amarillas delgadas (Fig. 17).

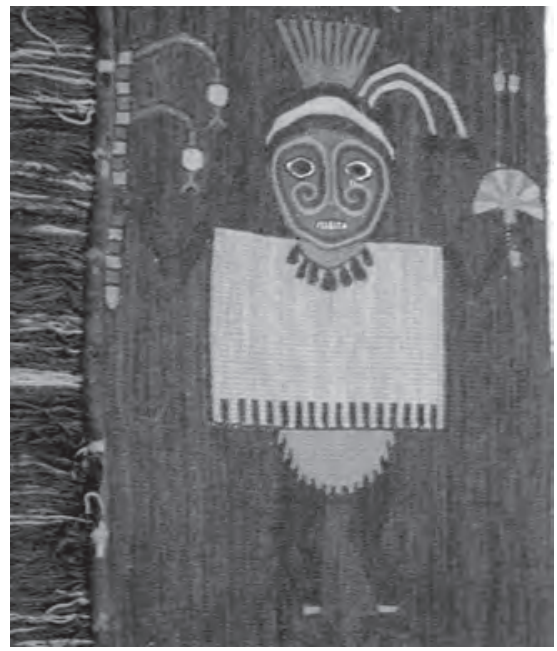

Figura 16. Personaje E, masculino, con penacho y abanico. Fotografía de W. Salas, cortesía del MAAUNMSM, 2004

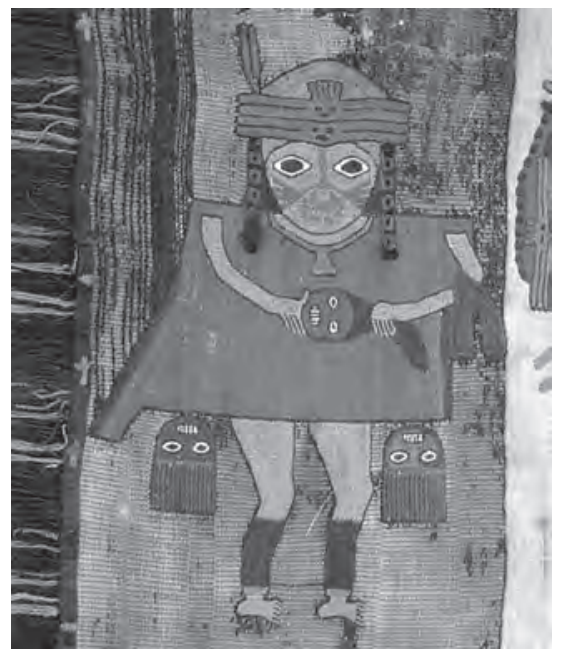

Figura 17. Personaje H, femenino, lleva una kallapa en el tocado. Fotografía de W. Salas, cortesía del MAA-UNMSM, 2004 
En síntesis, las prendas masculinas (uncus, faldellines y taparrabos) y de las femeninas (túnicas, anacos y llicllas) representados en el manto presentan tamaños y acabados variados. A partir de ellas hemos podido distinguir cinco personajes masculinos: B, C, D, E y G, y tres femeninos: A, F y H. En cuanto a los tocados compuestos por plumas, penachos, turbantes y peinados, observamos que hay personajes que ostentan tocados simples y otros sumamente complejos. El cuadro de la página siguiente resume los elementos correspondientes.

\begin{tabular}{|c|c|c|c|c|c|c|c|c|}
\hline TOCADOS & \multicolumn{8}{|c|}{ PERSONAJES } \\
\hline Elementos: & A & B & c & D & E & F & G & $\mathrm{H}$ \\
\hline $\begin{array}{l}\text { Punta de } \\
\text { Proyectil }\end{array}$ & & $\mathrm{X}$ & $\mathrm{X}$ & & & & & \\
\hline Penachos & & & & $\mathrm{X}$ & & & $\begin{array}{c}\mathrm{X} \\
\text { (pequeño) }\end{array}$ & \\
\hline Turbante largo & & $\mathrm{X}$ & $\mathrm{X}$ & & & $\mathrm{X}$ & & \\
\hline $\begin{array}{l}\text { Turbante enro- } \\
\text { llado }\end{array}$ & & & & & $\mathrm{X}$ & & $\mathrm{X}$ & $\mathrm{x}$ \\
\hline Diademas & & $X(2)$ & & $X(2)$ & $\mathrm{X}(1)$ & $X(2)$ & & $X(2)$ \\
\hline $\begin{array}{l}\text { Adornos en el } \\
\text { cabello }\end{array}$ & & $\mathrm{X}$ & & $\mathrm{X}$ & & $\mathrm{X}$ & & $\mathrm{X}$ \\
\hline $\begin{array}{l}\text { Cabellos } \\
\text { Trenzados }\end{array}$ & & $\mathrm{X}$ & & $\mathrm{X}$ & & $\mathrm{X}$ & & $\mathrm{X}$ \\
\hline $\begin{array}{l}\text { Vincha: cinta o } \\
\text { "llauto" }\end{array}$ & $\mathrm{X}$ & & & & & & & \\
\hline Otros: & $\begin{array}{l}\text { Serpientes } \\
\text { en la } \\
\text { cabeza }\end{array}$ & $\begin{array}{l}\text { Serpientes } \\
\text { en el } \\
\text { rostro }\end{array}$ & & & $\begin{array}{c}\mathrm{X} \\
\text { Cabellos }\end{array}$ & & Colgantes & $\begin{array}{l}\text { Instrumento } \\
\text { textil: "kalla- } \\
\text { pa" }\end{array}$ \\
\hline
\end{tabular}

Subrayamos que las puntas de proyectil y los penachos solo aparecen en los personajes masculinos: $\mathrm{B}$ y $\mathrm{C}$ con las primeras, y D y G con los segundos. Los turbantes largos son usados por personajes masculinos y femeninos: B, C y F. Los turbantes enrollados sin colgar solo se ven en personajes masculinos: E y G. Las diademas están presentes en personajes masculinos y femeninos: B, D, E, F y H. La diadema del personaje $\mathrm{E}$ es diferente al resto.

Los adornos en el cabello de discos sobre los cabellos trenzados se observan en personajes de ambos sexos: B, D, F y H. El personaje A es el único cuyo tocado no comparte ningún elemento en común con el resto. El personaje $\mathrm{E}$ tiene una diadema deferente a la del resto; y $\mathrm{G}$ con un penacho pequeño de plumas.

Además de los tocados, se puede apreciar el uso de una serie de complementos como narigueras, collares, abanicos, cabezas trofeo, ajorcas y báculos con punta, cuya distribución se resume en el cuadro de la página siguiente.

\section{DistRIBUCión ESPACIAL DE LOS PERSONAJES}

En cada una de las bandas longitudinales hay catorce personajes dispuestos en forma horizontal. En la banda longitudinal superior los catorce personajes están colocados horizontalmente con la cabeza dirigida a la derecha, mientras los pies se disponen de forma alternada: (el primer personaje tiene los pies apuntando hacia arriba, y el siguiente apuntando hacia abajo). En la banda longitudinal inferior, los catorce personajes están colocados de igual manera: horizontal con la cabeza dirigida a la izquierda, igualmente los pies se disponen de forma alternada. Las dimensiones de las figuras son de $20-22 \mathrm{~cm}$. de largo, por 12-13 cm. de ancho. 
Lourdes Chocano / Análisis de los personajes del Manto Blanco: Una interpretación iconográfica

\begin{tabular}{|c|c|c|c|c|c|c|c|c|}
\hline \multirow[t]{2}{*}{ OBJETOS COMPLEMENTARIOS } & \multicolumn{8}{|c|}{ PERSONAJES } \\
\hline & A & $\mathrm{B}$ & $\mathrm{C}$ & $\mathrm{D}$ & $\mathrm{E}$ & $\mathbf{F}$ & G & $\mathrm{H}$ \\
\hline Abanicos & & $\mathrm{X}$ & & & & & $\mathrm{X}$ & \\
\hline Collares & & & & $\mathrm{X}$ & & & $\mathrm{X}$ & $\mathrm{X}$ \\
\hline Cabezas (humanas) & & & & $\mathrm{X}$ & & $\mathrm{X}$ & & $\mathrm{X}(3)$ \\
\hline Cabezas pequeñas (humanas) & & & & & & $\mathrm{X}$ & & \\
\hline Narigueras & & & & $\mathrm{X}$ & & & & $\mathrm{X}$ \\
\hline Báculos de dos colores & & & $\mathrm{X}$ & $\mathrm{X}$ & $\mathrm{X}$ & & & \\
\hline Ajorcas & $\mathrm{X}^{1}$ & $\mathrm{X}$ & $\mathrm{X}$ & $\mathrm{X}$ & $\mathrm{X}$ & $\mathrm{X}$ & $\mathrm{X}$ & $\mathrm{X}^{2}$ \\
\hline Instrumentos (textiles) & $\mathrm{X}^{3}$ & & & & & & & $\mathrm{X}$ \\
\hline Varas de dos colores con sonaja & & & $\mathrm{X}$ & & & & $\mathrm{X}$ & \\
\hline Algodones & $\mathrm{X}^{4}$ & & & & & & & \\
\hline Otros objetos & $\mathrm{X}$ & $\mathrm{X}^{5}$ & & & & & & $\mathrm{X}$ \\
\hline Otros objeto: accesorios & & & & & & $X^{6}$ & & \\
\hline
\end{tabular}

1 Las ajorcas del personaje A son más gruesas y tienen decoración son el único personaje con este tipo.

2 Las ajorcas del personaje $\mathrm{G}$ están acompañadas de una especie de medias o escarpines. Es el único personaje con este tipo; para ambos personajes ver fotografías.

3 Huso con un ovillo de algodón.

4 Motas de algodón con rostros.

5 Antara.

6 Tupus que sujetan una lliclla.

En las bandas verticales superiores e inferiores: hay un total de dos personajes en cada una, es decir, ocho personajes en total. En la banda superior vertical izquierda, los dos personajes están erguidos mirando de frente, mientras que en la banda superior vertical derecha, los dos personajes están erguidos pero colocados de cabeza. Los pies de los personajes también han sido orientados de forma alternada; apuntando en direcciones opuestas. En la banda vertical inferior izquierda los dos personajes están erguidos mirando de frente, la orientación de los pies sigue el patrón descrito anteriormente: alternación de la dirección. Lo mismo ocurre con los de la banda inferior vertical derecha, los personajes están erguidos mirando de frente salvo que están de cabeza. En todas las bandas verticales, las figuras son más pequeñas de 13 a $12 \mathrm{~cm}$ de largo por 8 a $9 \mathrm{~cm}$ de ancho.

La distribución de los personajes de las bandas decorativas presentan una oposición diagonal espejo que describimos a continuación: Los personajes en el banda longitudinal superior van en el siguiente orden de izquierda a derecha: H, G, F, E, D, C, B, A, H, G, F, E, D y C. Los personajes en la banda longitudinal inferior de izquierda a derecha son: C, D, E, F, G, H, A, B, C, D, E, F, G y H. Como resultado tenemos que cada personaje en el borde inferior se refleja de modo idéntico, en el borde superior en diagonal con los mismos colores y disposición. Por ejemplo, tanto el personaje $\mathrm{H}$, en la esquina superior izquierda como el de la esquina opuesta, llevan túnica verde oscuro y los brazos y piernas están bordadas en color rojo.

Los personajes de los bordes verticales también presentan una oposición diagonal. Sin embargo, en la banda vertical superior izquierda hay dos personajes E y D, su opuesto diagonal corresponde a la banda vertical inferior derecha a los personajes; pero los personajes son D y C ambos dispuestos de cabeza. De modo que sólo hay correspondencia entre el personaje D, mientras que los personajes E y C no se corresponden. En los otros dos bordes opuestos están: en el vertical superior derecho los personajes B y A de cabeza, y en el borde vertical inferior izquierdo sus correspondientes opuestos: A y B erguidos. (Ver gráfico 18, 19).

En el cuadro observamos que 80 de las 120 figuras son masculinas y sólo 40 son femeninas. 


\begin{tabular}{|c|c|c|c|c|c|c|}
\hline Personajes & $\begin{array}{c}\text { Bandas } \\
\text { Superiores }\end{array}$ & $\begin{array}{c}\text { Bandas infe- } \\
\text { riores }\end{array}$ & $\begin{array}{c}\text { Campo } \\
\text { central }\end{array}$ & $\begin{array}{c}\text { Total } \\
\text { Masculinos }\end{array}$ & $\begin{array}{c}\text { Total } \\
\text { Femeninos }\end{array}$ & Total \\
\hline A & 2 & 2 & 13 & -- & 17 & -- \\
\hline$B$ & 2 & 2 & 11 & 15 & -- & -- \\
\hline C & 2 & 3 & 8 & 13 & -- & -- \\
\hline$D$ & 3 & 3 & 16 & 21 & -- & -- \\
\hline$E$ & 3 & 2 & 11 & 16 & & -- \\
\hline$F$ & 2 & 2 & 10 & -- & 14 & -- \\
\hline$G$ & 2 & 2 & 10 & 14 & -- & -- \\
\hline$H$ & 2 & 2 & 5 & -- & 9 & - \\
\hline & & & & & & -- \\
\hline Masculinos & 12 & 12 & 56 & 80 & -- & $\mathbf{4 0}$ \\
\hline Femeninos & 6 & 6 & 28 & -- & 40 & $\mathbf{8 0}$ \\
\hline Total & 18 & 18 & 84 & -- & -- & $\mathbf{1 2 0}$ \\
\hline
\end{tabular}

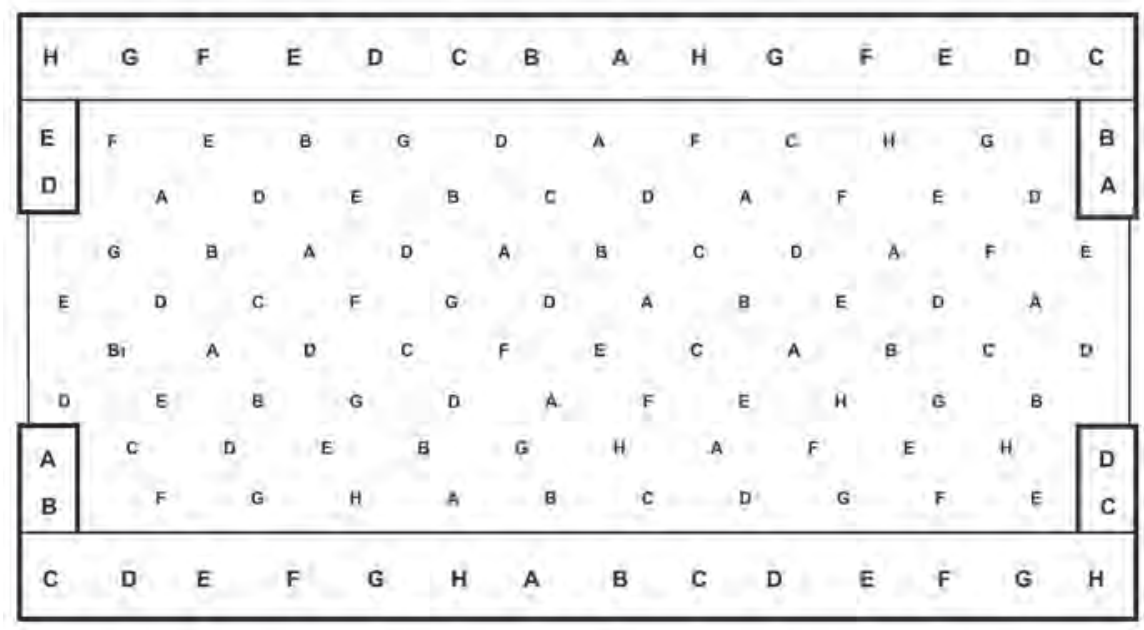

Figura 18. Distribución de los 120 personajes en el Manto Blanco. Dibujo de Lourdes Chocano.

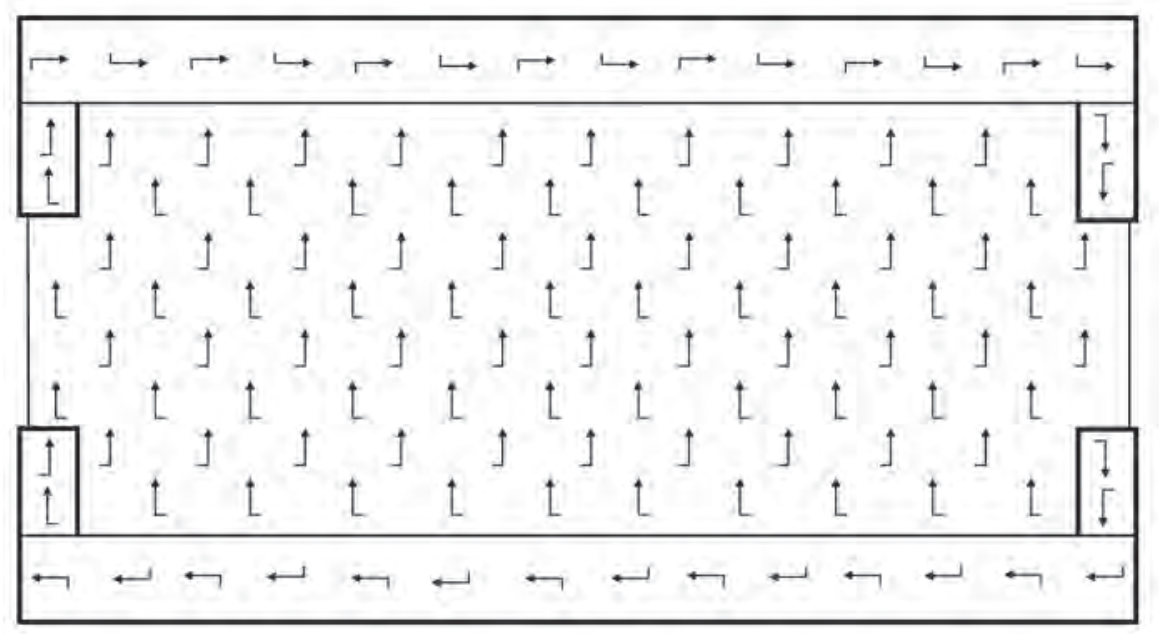

Figura 19. Orientación de los 120 personajes en el Manto Blanco. Dibujo de Lourdes Chocano. 


\section{LECTURA DEL SISTEMA CROMÁTICO DEL MANTO}

La aparente falta de coherencia en la distribución de colores en las imágenes es característica de muchos mantos Paracas donde aparecen los personajes o motivos sin un orden secuencial ni ritmo cromático. Sin embargo, la investigadora Mary Frame (1994: 10) sugiere que el orden obedece a las estructuras de la técnica textil: el "Sprang ${ }^{10}$ y los trenzados, procedimientos que consisten en entrelazar alternadamente hilos de diversos colores. Así la lectura de la distribución de colores en las figuras que aparecen en los mantos no se puede hacer mediante una lectura lineal (ni horizontal ni vertical), sino más bien diagonal y ondulante, siguiendo el cruce de los elementos o hilos de colores. Agrega que este patrón textil se desarrolló desde épocas tempranas y que se repite constantemente en todas las culturas y periodos en el área andina.

Basándome en ese planteamiento, voy a proponer una lectura diagonal de ciertos atributos de los personajes. Tomaré el color de los uncus y túnicas, y el color de las extremidades (brazos y piernas de los personajes).

- La lectura diagonal de los colores de la vestimenta, de derecha a izquierda y de abajo hacia arriba, da un resultado de 14 diagonales con una secuencia de dos colores en todos los casos excepto en el primero:

$1^{\text {a }}$ diagonal (un solo personaje): morado

$2^{\text {a }}$ diagonal (cuatro personajes): rojo-amarillo-rojo-amarillo.

$3^{\text {a }}$ diagonal (seis personajes): morado-verde-morado-verde-morado-verde.

La $4^{\mathrm{a}}$ diagonal (siete personajes) coincide con la $2^{\mathrm{a}}$ en la secuencia rojo-amarillo; la $5^{\mathrm{a}}$ diagonal (nueve personajes) coincide con la $3^{\mathrm{a}}$, pero invierte el orden a verde-morado-verde-morado, hasta el noveno personaje con vestimenta de color verde. Luego se repiten de forma alternada las secuencias rojo-amarillo y la de verde-morado en las siguientes diagonales. La diagonal 14 (dos personajes) cierra la serie con la secuencia rojo- amarillo.

- La lectura diagonal de los colores de las extremidades, de izquierda a derecha y de arriba a abajo, resulta en trece diagonales con una secuencia de tres colores, excepto en la primera.

$1^{\text {a }}$ diagonal (un personaje): con extremidades de color verde.

$2^{\text {a }}$ diagonal (tres personajes): morado-rojo- morado.

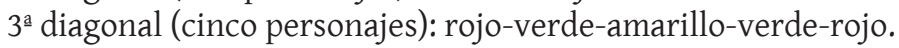

$4^{\text {a }}$ diagonal (seis personajes): amarillo-morado-rojo-morado-amarillo-morado.

$5^{\text {a }}$ diagonal (ocho personajes) morado-rojo-verde-amarillo-verde-rojo-verde-amarillo.

La $6^{\underline{a}}$ diagonal coincide con la $3^{a}$. La $7^{a}$ diagonal coincide con la $4^{a} ;$ y así sucesivamente hasta la diagonal $12^{\mathrm{a}}$. La diagonal $13^{\mathrm{a}}$ (tres personajes) cierra la serie con la secuencia amarillo-moradorojo.

Esta lectura en diagonal del orden cromático se puede repetir tanto para los colores de las extremidades como para los de la vestimenta, en orden inverso, es decir de izquierda a derecha y de abajo a arriba, dando el resultado de nuevas secuencias armónicas.

En la figura 20 cada tonalidad se presenta con signos convencionales según la secuencia cromática encontrada en las vestimentas y en las extremidades, lo que permite una mejor apreciación del ritmo cromático. El esquema resultante semeja un trenzado de cuatro colores y ocho hebreas.

10 Frame incluye en la denominación Sprang tres tipos de técnica de torsión: el entrelazado, el enlazado oblicuo y el entretejido oblicuo 


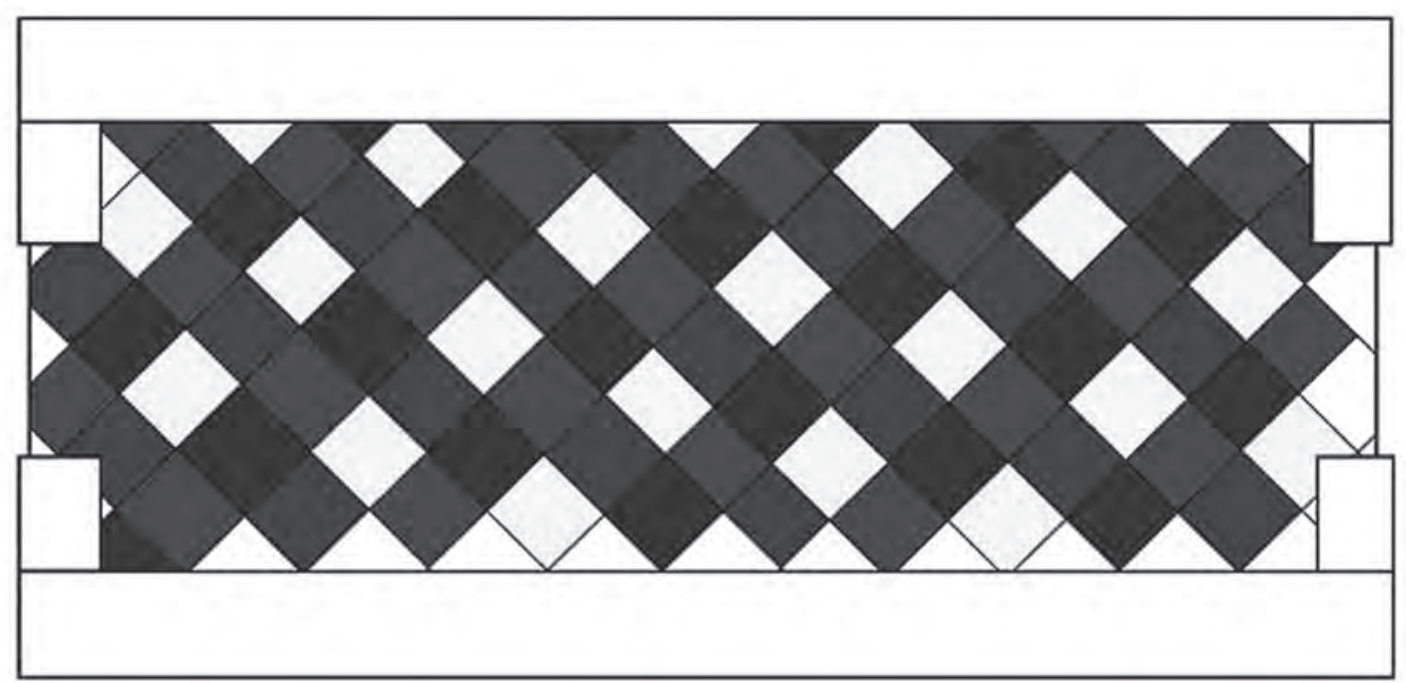

Figura 20. Ritmo cromático según el color de las vestimentas de los personajes en el Manto Blanco. Dibujo de Lourdes Chocano.

\section{INTERPRETACIÓN ICONOGRÁFICA Y CONCLUSIONES}

En el manto blanco encontramos el retrato de un conjunto de personajes que participa en un ritual que posiblemente estuvo relacionado a la actividad textil, tal como lo permite suponer la interpretación de una serie de accesorios que portan los distintos personajes. El personaje A (al que atribuyo el género femenino) lleva en la mano un instrumento que parece ser un huso con ovillo y copos de algodón con rostro, por lo cual podría personificar a una hilandera. Por otro lado, el "llauto" que lleva tiene figuras de serpientes, que en el arte Paracas representan el cabello de individuos con poderes chámanicos (Paul 1982: 46-48). Por tanto este personaje A combina los poderes chámanicos y la producción de hilos. La retorsión en los hilados también evoca la figura de la serpiente sinuosa, retorcida y colorida que se enrosca. También está ligada al agua y a la tierra: el agua que discurre en la superficie en forma de ríos y riachuelos es análoga a la figura serpentina y a la del los hilos entretejiéndose en un manto. Pienso que por ser el arte textil tan importante en Paracas debió considerarse a los que lo ejecutaban como dotados de ciertos poderes, ya que transformaban las fibras en brillantes hilos para bordar los sofisticados diseños que se aprecian en los ajuares funerarios. Por ello es posible pensar que se representara míticamente el oficio de hilandera en ritos y festividades.

El personaje B aparece tocando una antara de cinco tubos, semejante a la que el equipo de Tello recuperó en las viviendas subterráneas de Arena Blanca, hecha de arcilla (Tello 1979: 308). De manera que la música de antara puede considerarse como un elemento relevante para evento ritual que se representa en este manto. En algunas versiones el personaje B está representado con cuatro elementos: abanicos de plumas, serpientes, diadema de oro y una antara, pero no porta cabezas cercenadas. Sin embargo su papel como ejecutante de la música en un evento ritual y también el atributo de los abanicos puede relacionarse a un personaje que evoca el poder del viento y de las aves, en lo cual se vincularía al cóndor representado por el personaje C. A su vez, el atributo de las serpientes lo relaciona con el agua, los hilos y el poder chamánico.

El personaje masculino $\mathrm{C}$ representa a un cóndor y aparece en otros especímenes como en el en otras piezas textiles Paracas de colecciones de museos privados extranjeros (Frame 2008: 259). 
Su aparición en el evento ritual representado en el manto blanco puede sugerir al realizarse sacrificios de animales, esta ave habría podido alimentarse con los despojos resultantes. El personaje empuña unas sonajas, instrumentos musicales que probablemente sirvieron para marcar un ritmo de danza.

El personaje D es el mismo que aparece en una esclavina de la colección del MAA de la UNMSM y en un manto de la colección del Museo de Arte de Lima. Este personaje es el único que lleva un gran tocado de plumas, junto con diademas de oro, y porta una cabeza cercenada, pero no lleva serpientes. Las plumas que destacan en su parafernalia indican una relación con los poderes eólicos, los cuales no podían ser ignorados por los Paracas en la medida en que han perfilado el paisaje de dunas de la bahía.

El personaje E también aparece en una faldellín Paracas (Frame: 2008-251). Su diadema es más simple que las de otros personajes. Su tocado tipo malla es semejante a los encontrados en el fardo 217 perteneciente a un individuo de sexo masculino (Yacovleff y Muelle 1934). Tal como se ha descrito va armado y lleva una mano cercenada, posiblemente una reliquia que alude que algún episodio bélico, por lo que se puede pensar que es la personificación de un guerrero ${ }^{11}$.

El personaje $\mathrm{F}^{12}$ también aparece en un manto del fardo 217 -Museo de Arqueología, 10 (12/8802)estudiado en 1926 por Muelle y Yacovleff (1934). El mismo personaje se encuentra en el manto número 7 del fardo 382 del mismo museo y en otras piezas pertenecientes a colecciones extranjeras (Frame 2008: 252).

El personaje $G$ también aparece en un tejido del fardo 18 del Museo de Arqueología y Antropología e Historia. En el fardo 217 se encontró un penacho igual al que lleva este personaje (Yacovleff y Muelle 1934: 147); aparece además en otros tejidos Paracas de colecciones extranjeras (Frame 2008: 259). Sus accesorios plumas, abanico y penacho, y el hecho de portar sonajas le da un papel en el ritual equivalente a los personajes B y D.

Finalmente, el personaje $\mathrm{H}$ es femenino por el tipo de túnica, la horquilla (kallapa) que en el tocado indica su vinculación con la actividad del hilado. Al igual que los personajes femeninos $\mathrm{F}$ y $\mathrm{H}$, lleva cabezas cercenadas entre las manos y colgadas de las túnicas. Este detalle, junto con el hecho de que ostentan doble diadema, el rostro pintado y narigueras, además de cabellos trenzados pueden señalar que tenía un estatus de autoridad chamánica, en la que la violencia estaba presente y era un criterio de jerarquía de acuerdo con la cantidad de cabezas cortadas. Cabe referirse a que en contextos aymaras se cuenta que en las guerras interétnicas el hombre casado que cortaba la cabeza de un enemigo, la entregaba después a su esposa (Arnold 2000: 11). En Paracas no se ha clarificado el uso de las cabezas cercenadas. Es posible que, antes que ser el resultado de acciones guerreras, se tratara de representaciones de cabezas de ancestros que funcionarían como talismanes o reliquias. Tal vez aquellos personajes que no portaban cabezas consigo estaban supeditados a los portadores de cabezas. La pintura facial en los rostros de la mayoría de los personajes (A, C, E, F y G) los dotaba de mayores facultades para atraer poderes mágicos.

En Moche se ha podido identificar que la mujer participó como chamana, y no sería extraño que esta función se pueda haber cultivado en todo el ámbito costeño. Esto nos lleva a reflexionar y plantear nuevas investigaciones en Paracas y rol de la mujer en esta cultura ${ }^{13}$.

11 Peters (2009: 34) describe los objetos bélicos encontrados en fardos de individuos masculinos en Paracas Necrópolis.

12 Frame designa a este personaje con la letra "A". Dicho personaje aparece en una falda Paracas acompañado por los personajes D, E y F (Frame 2008: 241).

13 Los hallazgos de la señora de Cao en El Brujo por el arqueólogo Régulo Franco, cuyo ajuar compuesto por objetos de oro entre los cuales había agujas de oro, así como otros elementos que la ligaban al poder chamánico pueden ser apreciados en el Museo de Sitio de Cao. 
En síntesis dado el hecho de que la producción de tejidos fue central en la expresión cultural de los Paracas, no es imposible pensar que sus ejecutores y creadores tuvieran un rol fundamental en la vida ritual de esta sociedad. El papel de los personajes femeninos portando instrumentos de tejido en el manto blanco nos hace percibir que hay que atender a la posible relación entre arte textil y poder chamánico.

\section{Agradecimientos}

Al Museo de Arqueología y Antropología de San Marcos donde trabajé en la conservación y montaje del Manto Blanco. A Wilbert Salas y José Martínez del Archivo Tello del MAA (2004-2005), a Juan Roel y Víctor Paredes. Al Antropólogo Harold Hernández Lefranc miembro del Comité Directivo del 2004-2005. A la Ing. Rosa Medina del Laboratorio de Microscopía Electrónica de la Escuela Académica Profesional de Ingeniería Geológica de la UNMSM. A las estudiosas de la problemática de Paracas Dra. Mary Frame y la Dra. Ann Peters. Finalmente a la Mg. Olga Sulca del Comité Organizador de la $1^{\circ}$ Jornada de sobre estudio y conservación de textiles en San Miguel de Tucumán.

\section{BiBLIOGRAFÍA}

ARNOLD, Denise

2000 "Convertirse en persona. El tejido: La terminología aymara de un cuerpo textil". En: Victoria Solanilla Demestre ed. Actas de la I Jornada Internacional sobre Textiles Precolombinos: 9-28; Barcelona: Universidad Autónoma de Barcelona-Instituto Catalán de Cooperación Iberoamericana.

\section{CARRIÓN CACHOT, Rebeca}

1923 “La mujer y el niño en el antiguo Perú". Revista Inca Vol. 1, no 2. abril/junio 1923: 329-354.

1931 "La indumentaria en la antigua cultura Paracas". Wiracocha:Revista Peruana de Estudios Antropológicos, $1(1)$.

DWYER, Ann

1979 "The Chronology and Iconography of Paracas-Style Textiles". The Junius B._Bird Pre-Columbian Textiles Conference March 7-8, 1978. Washington, D.C.: The Textile Museum, Dumbarton Oaks.

\section{DESROSIERS, Sophie}

1992 "Las técnicas de tejido ¿tienen un sentido? Una propuesta de lectura de los tejidos andinos". Revista Andina: Tejido Andino: Pasado y Presente (julio) nº 1, Año 10: 7-46.

FRAME, Mary

1991 "Structure, Image, and Abstraction. Paracas Necropolis Headbands as System Templetes" En: Ann Paul ed. Paracas Art \& Architecture. Object \&Context in South Coastal Peru: 110-171. Iowa City: University of Iowa.

1994 “Las imágenes visuales de estructuras textiles en el arte del antiguo Perú". Revista Andina: Pasado y Presente, 12 (2): 295-372.

2007 "Las prendas bordadas de la necrópolis de Wari Kayan". Hilos del Pasado el aporte francés al legado Paracas. Lima: INC. MNAAHP. Fundación Franco-Peruana. Embajada de Francia. pp. 65-73.

2008 "Representación de género, jerarquía y otras relaciones en los bordados Paracas Necrópolis" Arqueología y Sociedad 19: 241-264.

2009 "Desenvolviendo las dimensiones de significado de los bordados de Paracas Necrópolis". En: Mantos para la eternidad Textiles Paracas del antiguo Perú. Museo de la América, Madrid Set. 2009/ Febrero 2010. INC. Ministerio de Cultura. España.

FUNG, Rosa

2004 "El arte textil en el antiguo Perú: Sus implicancias económicas, sociales, políticas y religiosas" en Quehaceres de la Arqueología Peruana. Compilación de Escritos. MAA, CCSS, UNMSM. pp. 225-244.

GUAMAN POMA DE AYALA, Felipe

1987 Nueva Crónica y buen gobierno. Tomo A. Edición de John Murra, Rolena Adorno y Jorge L. Urioste. Historia 16. Madrid. 
ISLA, J. y Markus REINDEL

2007 "Los Paracas del Sur. Una nueva perspectiva desde los valles de Palpa". Hilos del Pasado el aporte francés al legado Paracas. Lima: INC. MNAAHP. Fundación Franco-Peruana. Embajada de Francia. pp. 79-91

JAKE, K.

1991 "Physical and Chemical Analysis of Paracas Fibers" En Ann Paul ed. Paracas Art \& Architecture: Object \&Context in South Coastal Peru. Iowa City: University of Iowa. pp. 222-239.

JIMÉNEZ, María Jesús

2009 “Técnica Textiles en los Tejidos Paracas". En: Mantos para la eternidad Textiles Paracas del antiguo Perú. Museo de la América, Madrid Set. 2009/Febrero 2010. INC. Ministerio de Cultura. España.

KAUFFMAN DOIG, Federico

1999 El Arte Textil de Paracas. Ed. José Antonio de Lavalle y Rosario de Lavalle Cárdenas. AFP Integra. pp. 143-234.

LEÓN, Elmo

2007 "Cronología de los fardos funerarios de Wari Kayan, Paracas Necrópolis". En: Hilos del Pasado. El aporte francés al legado Paracas. Lima: INC. MNAAHP. Fundación Franco-Peruana. Embajada de Francia. pp. 33-47.

LUMBRERAS, Luis

1969 De los pueblos, las culturas y las artes del antiguo Perú. Francisco Moncloa ed. Lima.

Museo de la América

2009 Mantos para la Eternidad. Textiles Paracas del antiguo Perú. Museo de la América, Madrid Set. 2009/ Febrero 2010. INC. Ministerio de Cultura. España.

PAUL, Ann

1982 "The symbolism of Paracas Turbans: A consideration of style, serpents, and hair". Ñawpa Paccha, $\mathrm{n}^{\mathrm{2}}$ 20: 41-60. Berkeley, California.

1986 “Un manto Paracas y la coloración de sus figuras". Boletín de Lima, 48: 19-30.

1991 "Paracas. An Ancient Cultural Tradition on the South Coast of Peru". En: Ann Paul ed. Paracas Art \& Architecture. Object \&Context in South Coastal Peru. Iowa City: University of Iowa. pp. 1-34.

1991 "Paracas Necropolis Bundle 89. A descripction and Discussion of Its Contents". En Ann Paul ed. Paracas Art \& Architecture. Object \&Context in South Coastal Peru (Ann Paul, ed.). Iowa City: University of Iowa. pp. 1-34.

2002 "Las múltiples capas de significación de un tejido Paracas Necrópolis". En Victoria Solanilla Demestre, ed. Actas II Jornadas internacionales sobre textiles precolombinos. Universidad Autónoma de Barcelona-Instituto Catalán de Cooperación Iberoamericana. pp. 177-189.

PETERS, Ann

1991 "Ecology and Society in Embroidered Images from the Paracas Necropolis" En: Ann Paul ed. Paracas Art \& Architecture. Object \&Context in South Coastal Peru. Iowa City: University of Iowa. pp. 240-314.

2003 "Cabeza y Tocado: Significados en Paracas, Topará y Nasca" En: Tejiendo Sueños en el Cono Sur Textiles andinos: Pasado, presente y futuro. Actas del Simposium ARQ 21. 51 Congreso Internacional de Americanistas. Victoria Solanilla Demestre ed. Santiago de Chile, julio de 2003.

2007 "La Necrópolis de Wari Kayan". En: Hilos del Pasado. El aporte francés al legado Paracas. LIma: INC. MNAAHP. Fundación Franco-Peruana. Embajada de Francia. pp. 23 - 32.

2009 "El cementerio de Paracas Necrópolis un mapa social complejo" En Mantos para la eternidad Textiles Paracas del antiguo Perú. Museo de la América, Madrid Set. 2009/Febrero 2010. INC. Ministerio de Cultura. España.

ROEL, Pedro y P. BORJA

2011 Anaco de Camilaca. Uso contemporáneo de un traje prehispánico. Ministerio de Cultura. Perú.

ROWE, Ann Pollard

2002 "Ica style women's dress". The Textile Museum Journal Volumes 40 and 41. 2001-2002: 98-117. Washington DC. 
STONE, Rebeca

1992 To weave for the Sun Ancient Andean textiles. New York: Thames and Hudson.

TELLO, Julio C.

2005 Paracas. Primera parte. Obras completas volumen II. Serie Clásicos Sanmarquinos. UAP. COFIDE. El fondo Editorial de San Marcos. CCSS. MAA-UNMSM.

TELLO, Julio C. y T. MEJÍA XESSPE

1979 Paracas II Parte, Cavernas y Necrópolis. Lima: Universidad Nacional Mayor de San Marcos.

YACOVLEFF, Eugenio y Jorge MUELLE

1934 "Un fardo funerario de Paracas". Revista del Museo Nacional, III (1-2): 63-153.

WOUTERS, Jan y N. ROSARIO

1999 "Los secretos de los tintoreros andinos" Iconos Revista peruana de conservación, arte y arqueología. Número 1. 1999-1. 